\title{
ARBORIZAÇÃO VIÁRIA DO MUNICÍPIO DE COLORADO, RS - BRASIL: ANÁLISE QUALI-QUANTITATIVA
}

\author{
Aline Pazinato Raber ${ }^{1}$, Gisele Sana Rebelato ${ }^{2}$ \\ (recebido em 08.10.2009 e aceito para publicação em 23.03.2010)
}

\begin{abstract}
RESUMO
A arborização urbana constitui um elemento de importância para a obtenção de níveis satisfatórios de qualidade de vida, proporcionando conforto aos habitantes das cidades. Considerando a importância de um estudo e de um planejamento que vise atender as necessidades da realidade local em relação à arborização, o presente trabalho objetivou fazer uma avaliação quali-quantitativa da arborização nas ruas e avenida do município de Colorado, RS. A arborização urbana foi analisada qualitativamente e quantitativamente. Encontraram-se 483 indivíduos arbóreos, pertencentes à 45 espécies, sendo Inga marginata a espécie mais freqüente com $21 \%$ dos indivíduos. Espécies nativas predominaram na arborização da cidade com 25 espécies representando $51 \%$ do total de indivíduos amostrados. Já as exóticas são representadas por 20 diferentes espécies. 0 Índice de diversidade de Shanonn $\left(\mathrm{H}^{\prime}\right)$ foi de 2,95, demonstrando uma diversidade intermediária, considerando as espécies exóticas que entraram na amostra. Quanto à abundância de árvores, foi encontrado para a cidade um número de 43 árvores por quilômetro de calçada, índice que pode ser considerado valor mediano. Contudo, considera-se indispensável o planejamento da arborização urbana e a realização de um plano prevendo espécies, critérios e técnicas adequadas para plantios em diferentes situações.
\end{abstract}

Palavras-chave: arborização urbana, planejamento, gestão ambiental, paisagismo.

\footnotetext{
1. Bióloga, Especialista em Biologia da Conservação e Tecnologias Ambientais, Universidade de Cruz Alta, Colorado/RS <apazinato@hotmail.com>;

${ }^{2}$. Mestre em Ecologia, Unicruz/Fac Portal Faculdades, Passo Fundo/RS < girebelato@ yahoo.com.br>.
} 


\title{
STREET AND AVENEW AFFORESTATION OF THE CITY OF COLORADO/RS, BRAZIL: QUALI-QUANTITATIVE ANALYSIS
}

\begin{abstract}
The urban forest is an important element for achieving satisfactory levels of quality of life, providing confort to the inhabitants to the cities. Considering the importance of a study and planning aimed at meeting the needs of the local situation in relation to afforestation, this study aimed to evaluate qualitative and quantitative stock street and avenue in the city of Colorado, RS. The urban forestry was analyzed qualitatively and quantitatively. There were found 483 individual trees belonging to 45 species, Inga marginata is the most frequent species with $21 \%$ of individuals. Native species predominate in reforestation of the city with 25 species representing $51 \%$ of the total individuals sampled. Since the exotic are represented by 20 different species. The diversity index Shanonn $\left(H{ }^{\prime}\right)$ was 2.95, demonstrating an intermediate diversity, considering the exotic species that entered the sample. The abundance of trees, was found to the city a number of 43 trees per mile of sidewalk, a rate that can be considered the median value. However, it is essential to the planning of urban forest planting and carrying out a plan providing species, criteria and proper techniques for planting in different situations.
\end{abstract}

Key words: urban forest, planning, environmental management, garden design. 


\section{INTRODUÇÃO}

A arborização urbana no Brasil é considerada um tema recente e de evolução lenta. A presença da vegetação arbórea urbana apresenta benefícios e problemas, sendo indispensável a sua contemplação no planejamento urbano. A importância do assunto requer o envolvimento das administrações públicas e das comunidades, cada qual cumprindo seu papel.

Para Graziano (1994), a vegetação urbana desempenha funções essenciais nos centros urbanos, do ponto de vista fisiológico, melhora o ambiente urbano por meio da capacidade de produzir sombra; filtra ruídos, ameniza a poluição sonora; melhora a qualidade do ar, aumentando o teor de oxigênio e de umidade, e absorvendo o gás carbônico; ameniza a temperatura, entre outros aspectos.

De acordo com Milano (1990), arborizar uma cidade, não significa apenas plantar árvores nas ruas, praças e jardins, e sim criar áreas verdes de recreação pública e proteger áreas verdes particulares. A arborização deve atingir objetivos específicos de ornamentação, de melhoria microclimática e de diminuição da poluição, entre outros, esta deve ser fundamentada em critérios técnico-científicos que viabilizem tais funções.

Um aspecto relevante referente ao plantio de árvores requer cuidados especiais, uma vez que, a escolha de espécies e locais inadequados poderá gerar diversos conflitos, entre eles cita-se: a poda drástica, o corte raso e o plantio de árvores exóticas, entre outros. Cabe ao poder público municipal planejar e orientar a comunidade em relação à ocupação do espaço territorial urbano mediante estudos ambientais, assim como, proporcionar à população a oportunidade de uma nova postura diante da arborização urbana, sensibilizando-a da importância das árvores à qualidade ambiental.

O planejamento urbano do município de Colorado,RS apresenta problemas decorrentes da aglomeração, falta de um plano de arborização, ocupação de áreas inadequadas, além do empobrecimento da qualidade ambiental. Devido à falta generalizada de planejamento, um dos muitos problemas para a efetivação da adequada arborização urbana é a dificuldade de compatibilização desta com as estruturas de melhorias básicas como a pavimentação, a rede elétrica, o saneamento, entre outros. 
Esta falta de planejamento da arborização urbana do município de Colorado/RS, hoje é percebida quando se caminha pelas ruas e avenida e depara-se com alguns problemas como, por exemplo, a falta de visibilidade, os passeios danificados, o contato das árvores com a rede elétrica, entre outros.

Em cidades, onde ocorre o planejamento da arborização, a preocupação é tornar o ambiente urbano diversificado quanto às espécies empregadas, mais homogêneo e envolvente com a paisagem circundante (MELO \& ROMANI, 2008). Milano (1994) afirma que a arborização urbana no Brasil tem sido realizada com raras exceções, sem planejamento. Neste contexto, a arborização de ruas requer que seja adequadamente planejada e mantida de forma sustentável, para assim obter a efetivação dos benefícios esperados.

De acordo com Dantas e Souza (2004), planejar a arborização é indispensável para o desenvolvimento urbano, para não trazer prejuízos para o meio ambiente. Além disso, a arborização é fator determinante da salubridade ambiental, por ter influência direta sobre o bem estar do homem, em virtude dos múltiplos benefícios que proporciona ao meio, pois contribui à estabilização climática, embeleza, fornece abrigo e alimento à fauna, bem como proporciona sombra e lazer nas praças, parques, jardins, ruas e avenidas de nossas cidades.

A relação entre as árvores e a população muitas vezes tem sido marcada pela ocorrência de conflitos provocados por falhas no planejamento da arborização urbana. Um aspecto importante da arborização de ruas se refere ao seu planejamento adequado, de forma que, ao se desenvolver, a árvore não entre em conflito com outras estruturas urbanas, como fiação aérea, tubulação subterrânea, o tráfego e outros (VILLARINHO, et al., 2005).

Os levantamentos qualitativos realizados em algumas cidades revelaram situações que comprometem o desenvolvimento satisfatório das espécies ao longo das vias públicas. Dentre os quais destacam-se: as condições do solo, o tamanho das covas, a área livre, o tutoramento, as podas, a inadequação de espécies ao espaço e uso urbano, entre outras.

De acordo com Souza et al. (1996), os objetivos do levantamento da arborização urbana, se resumem em conhecer o patrimônio arbóreo; definir uma política de administração em longo prazo; estabelecer previsões orçamentárias para o futuro; preparar um programa de gerenciamento das árvores; identificar a necessidade de manejo, definir prioridades nas intervenções; localizar áreas para plantio; localizar árvores com necessidade de tratamento ou remoção e utilizar a árvore como um vetor de comunicação. 
O presente trabalho justifica-se pela necessidade de um levantamento da situação atual da arborização do município de Colorado/RS, para um melhor planejamento urbano, pelo conhecimento técnico-científico e pela educação ambiental de seus habitantes e governantes. Diante disso, estima-se a urgente necessidade de buscar alternativas para a condução da política ambiental visando atender as tendências atuais de substituição dos sistemas de gestão ambiental, por modelos que elevem a qualidade de vida.

\section{MATERIAL E MÉTODOS}

\section{Caracterização da área}

O município, de colonização predominantemente italiana, possui uma área total de 286,178 km² e está situado na região do Planalto Médio (Micro Região 22 do Alto Jacuí), no centro norte do estado do Rio Grande do Sul, distando $297 \mathrm{Km}$ da capital Porto Alegre, apresentando como ponto central de localização as seguintes coordenadas geográficas: Latitude sul $28^{\circ} 31^{\prime 2} 26^{\prime \prime}$ e Longitude oeste 52 59 '39”, sendo a altitude da sede municipal de 428 metros. A umidade relativa do ar (média anual) é de $75 \%$ e a Temperatura Média Anual é de $18^{\circ} \mathrm{C}$ (IBGE, 2009).

A sede do município possui área de aproximadamente $2.631 .700,00 \mathrm{~m}^{2}$, conforme mapa cadastral do município na escala 1: 4.000 (PREFEITURA MUNICIPAL DE COLORADO, 2004), possuindo uma população de 3.744 habitantes e economia essencialmente agrícola.

\section{Coleta de dados}

Os dados foram coletados entre os meses de Março e Julho de 2009, em formulário próprio, com informações sobre a data da coleta, nomes das ruas e número das quadras selecionadas.

Foi realizado levantamento dos estudos já realizados no município de Colorado,RS. O método de inventário utilizado no levantamento foi de caráter quali-quantitativo em forma de amostragem, averiguando desta forma, a situação atual da arborização urbana. Para a realização deste trabalho, foram escolhidas as ruas de maior movimento (Rua Treze de Setembro, à esquerda da avenida; Avenida Boa Esperança, centro; Rua São José, à direita da avenida; e demais ruas que ligam as mesmas - sempre observando o noroeste como ponto inicial). Os dados referentes a cada quarteirão foram anotados em planilha específica, sendo a direção das medidas no sentido horário. 
O sistema de referência utilizado foi o mapa oficial da cidade na escala 1:4.000 (PREFEITURA MUNICIPAL DE COLORADO, 2004), com a identificação dos quarteirões como unidades amostrais. Nesta amostragem foram retirados aqueles que pertenciam à Área de Preservação Permanente (APP) ou praças. O levantamento quali-quantitativo foi realizado através de caminhadas pelas ruas e avenida, sendo que os indivíduos foram facilmente reconhecíveis, como árvores, ervas ou plântulas.

Conforme Rachid e Couto (1999), o emprego do método de amostragem casual simples, prescinde de informações sobre a quantidade de árvores existentes nas unidades amostrais e, é empregado sem censurar as unidades com baixo índice de arborização, além disso, não exige que as unidades amostrais sejam do mesmo tamanho.

Para cada quadra, através do método amostragem casual simples, obteve-se a abundância de árvores, expressas em "número de árvores por quilômetro de calçada", para isso foram anotados o total de árvores existentes, e demais medidas com o uso de trena, sendo: o comprimento de cada quadra e a largura de cada calçada (Figura 01). O total de quilômetros de calçada de um quarteirão foi estimado, somando-se aos comprimentos de cada uma das suas quadras, as larguras das calçadas, de maneira a obter-se o perímetro representado na Figura 01 pelo quadrado cinza. Com isso obteve-se a abundância de árvores, expressas em "número de árvores por quilômetro de calçada". A variável "número de árvores por quilômetro de calçada", foi definida como a razão entre duas características populacionais: número total de árvores existentes nas calçadas e o total de quilômetros de calçadas na área de estudo.

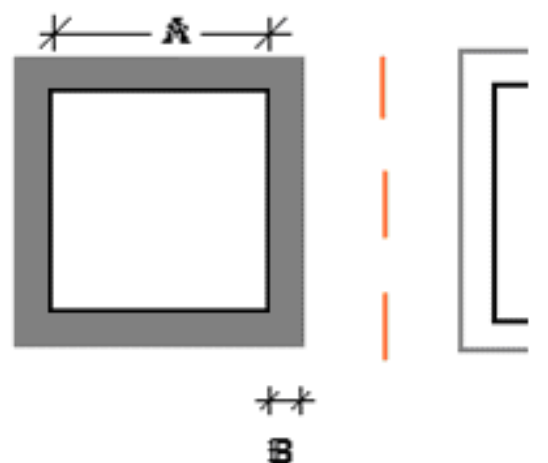

Figura 01. Representação de um quarteirão com as respectivas dimensões: A comprimento da quadra; B - largura média da calçada (adaptado de RACHID \& COUTO, 1999). 
Para a quantificação e qualificação da arborização realizou-se a identificação botânica, identificação em espécie nativa ou exótica para o Brasil, estado fitossanitário, localização se classificada como própria ou imprópria para o local onde se encontra (Interferência na fiação elétrica, nas calçadas, dificultando a visibilidade, entre outros), identificação dos pontos de intervenção e observações complementares. Os dados foram analisados pelo programa Microsoft Excel para Windows XP.

A identificação dos exemplares arbóreos foi através de sua fenologia, a maioria deles, através do caule e folha, e em alguns casos, frutos, sendo que, para o processo de identificação foi utilizada literatura específica (LORENZI, 2002a, LORENZI, 2002b, LORENZI, 2003).

Quanto aos aspectos físicos e sanitários, os exemplares arbóreos foram analisados conforme as seguintes categorias: morto - apresenta danos irreversíveis de pragas, doenças ou graves danos físicos; péssimo - apresenta estado geral de declínio, podendo ser causados por danos de pragas, doenças ou defeitos físicos; regular - vigor e condições médias, com sinais de pragas, doenças ou injúrias, necessitando de poda, reparo ou controle; bom - sem sinais de pragas ou injúrias e, ótimo - árvores vigorosas, em perfeitas condições.

Para analisar a diversidade, foi utilizado o índice de diversidade de Shannon-Weiner $\left(\mathrm{H}^{\prime}\right)$, por depender moderadamente da amostragem, cálculo simples e ser o mais utilizado em trabalhos sobre arborização urbana.

$$
H=-\Sigma_{i}^{s}=1 \text { pi Ln pi }
$$

em que:

$\mathrm{H}=$ índice de Shannon;

$\mathrm{s}=$ número de espécies; e

pi = proporção da amostra contendo indivíduos da espécie i.

O perímetro das quadras foi obtido com a utilização de um mapa da cidade fornecido pela Prefeitura Municipal de Colorado - RS. O índice de abundância foi calculado como número de árvores por quilômetro de calçada.

\section{RESULTADOS E DISCUSSÃO}

A importância do inventário da arborização urbana está no fato de que, por meio dele, conhecemos o patrimônio arbóreo e identificamos as necessidades de manejo. Um inventário deve fornecer um nível mínimo de informações que permita ao planejador tomar decisões adequadas de manejo. Um dos aspectos mais importantes do inventário é quando 
ele é realizado de forma a fornecer uma contínua atualização das informações (TAKAHASHI, 1994).

No inventário da arborização viária do município de Colorado,RS, foram percorridos aproximadamente 10.502 metros em 15 ruas e na avenida. Registrou-se a ocorrência de 483 indivíduos arbóreos, os quais encontram-se irregularmente distribuídos e pertencem a 45 espécies diferentes. O Ingá-feijão (Inga marginata), a Falsa canela (Cinnamomum burmanni), o Guabijú (Myrcianthes pungens) e o Ligustro (Ligustrum lucidum) foram as espécies mais freqüentes responsáveis por 48,24\% das plantas levantadas (Tabela 1), sendo o Ingá-feijão (Inga marginata) a espécie mais freqüente, com uma percentagem de $21,12 \%$.

Tabela 1. Espécies presentes na arborização viária do município de Colorado, abundância e freqüência relativa.

\begin{tabular}{|c|c|c|c|c|c|}
\hline $\begin{array}{l}\text { Família } \\
\text { botânica }\end{array}$ & Nome científico & $\begin{array}{c}\text { Nome } \\
\text { Comum }\end{array}$ & $\begin{array}{c}\text { Nativa }(\mathbf{N}) \text { ou } \\
\text { Exótica }(\mathrm{E})\end{array}$ & $\mathbf{N}$ & $\begin{array}{c}\text { Frequiência } \\
\text { relativa \% }\end{array}$ \\
\hline Aceraceae & Acer palmatum & $\begin{array}{c}\text { Acer do } \\
\text { Japão }\end{array}$ & $\bar{E}$ & 04 & 0,83 \\
\hline Anacardiaceae & Schinus moles & $\begin{array}{l}\text { Arroeira } \\
\text { piriquita }\end{array}$ & $\mathrm{N}$ & 06 & 1,24 \\
\hline Annonaceae & Rollinia sylvatica & Araticum & $\mathrm{N}$ & 01 & 0,21 \\
\hline Araucariaceae & $\begin{array}{c}\text { Araucaria } \\
\text { angustifolia }\end{array}$ & $\begin{array}{l}\text { Pinheiro } \\
\text { brasileiro }\end{array}$ & $\mathrm{N}$ & 01 & 0,21 \\
\hline Arecaceae & $\begin{array}{c}\text { Syagrus } \\
\text { romanzoffiana }\end{array}$ & $\begin{array}{l}\text { Coqueiro } \\
\text { jerivá }\end{array}$ & $\mathrm{N}$ & 24 & 4,97 \\
\hline \multirow[t]{2}{*}{ Bignoniaceae } & Tabebuia chrysotricha & Ipê amarelo & $\mathrm{N}$ & 08 & 1,66 \\
\hline & Tabebuia heptaphylla & Ipê roxo & $\mathrm{N}$ & 05 & 1,04 \\
\hline Bombacaceae & Ceiba speciosa & Paineira & $\mathrm{N}$ & 08 & 1,66 \\
\hline Boraginaceae & Cordia americana & Guajuvira & $\mathrm{N}$ & 06 & 1,24 \\
\hline Cupressaceae & Cupressus sp. & Cipreste & $\mathrm{E}$ & 14 & 2,90 \\
\hline Fabaceae & Tipuana tipu & Tipuana & $\mathrm{N}$ & 10 & 2,07 \\
\hline \multirow[t]{3}{*}{ Lauraceae } & $\begin{array}{l}\text { Cinnamomum } \\
\text { burmanni }\end{array}$ & Falsa canela & $\mathrm{E}$ & 54 & 11,18 \\
\hline & $\begin{array}{l}\text { Cinnamomum } \\
\text { canphora }\end{array}$ & $\begin{array}{c}\text { Canela } \\
\text { canphora }\end{array}$ & $\mathrm{E}$ & 17 & 3,52 \\
\hline & Persea americana & Abacateiro & $\mathrm{E}$ & 01 & 0,21 \\
\hline Leguminosae & Inga marginata & Ingá-feijão & $\mathrm{N}$ & 102 & 21,12 \\
\hline
\end{tabular}




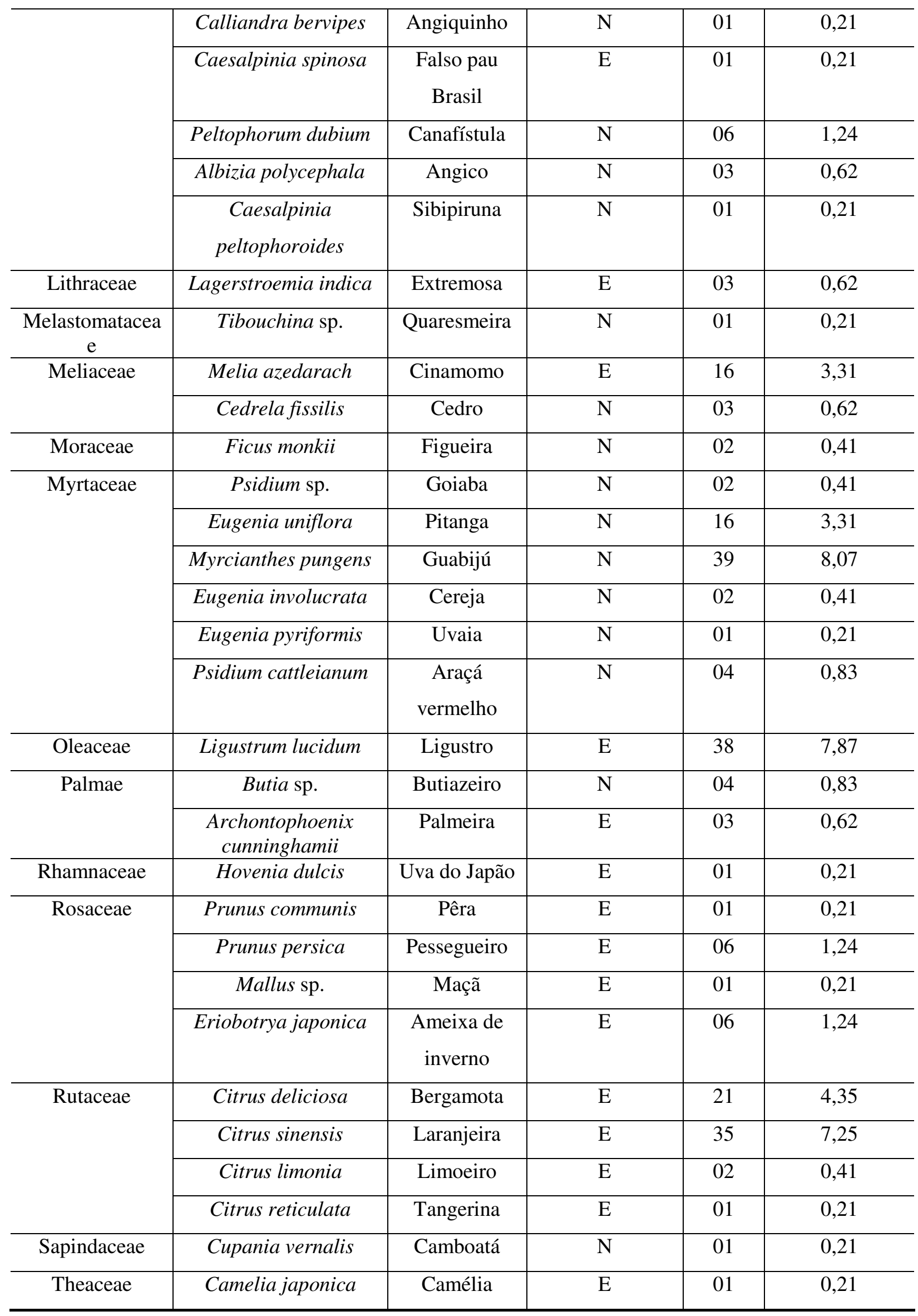


Em número de espécies, as plantas nativas são mais predominantes na arborização da cidade com 25 espécies, estando representadas em $51 \%$ do total de indivíduos amostrados.

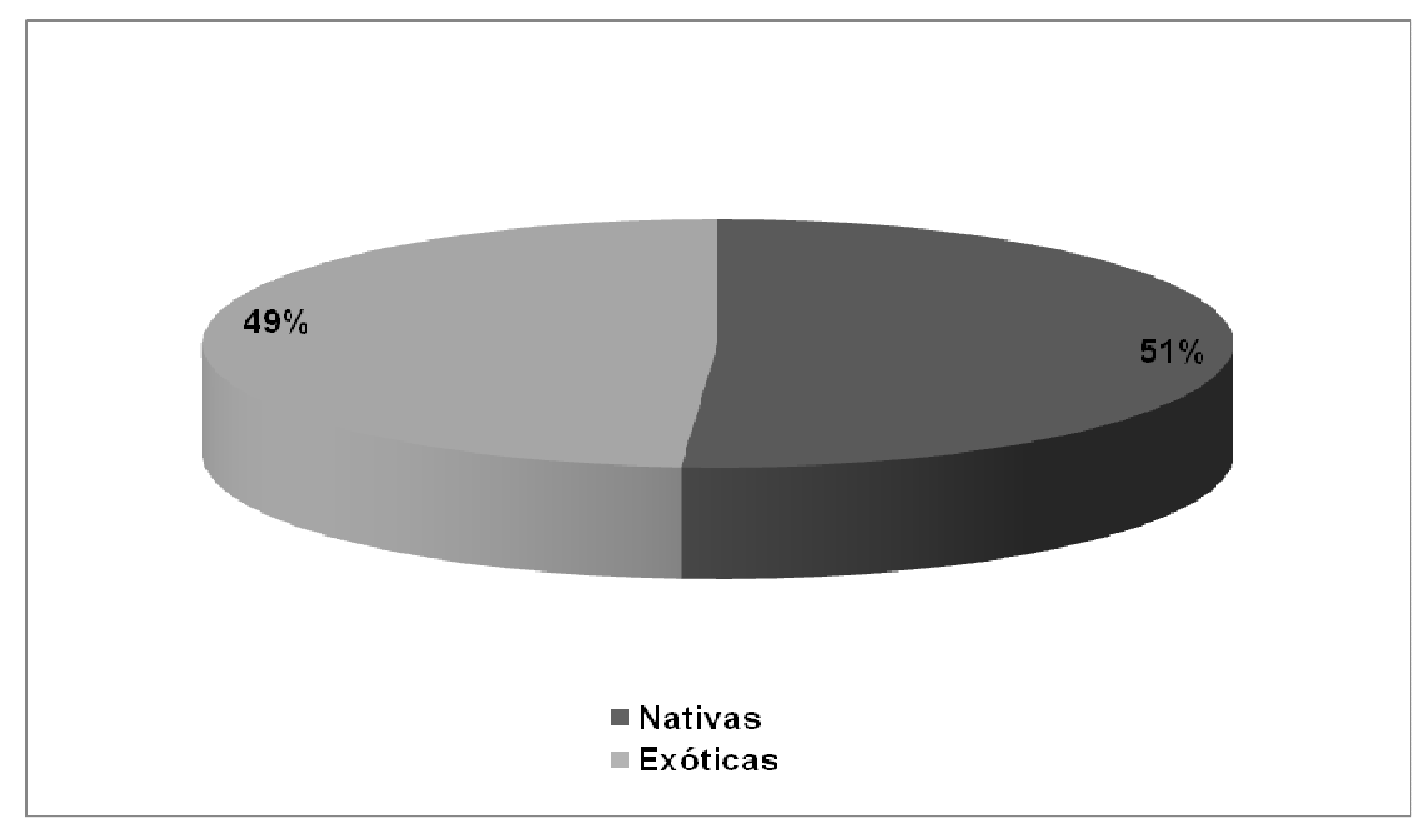

Figura 02 - Porcentagem de indivíduos nativos e exóticos ocorrentes na arborização urbana de Colorado,RS.

Das 53 quadras amostradas foram usados, para obtenção da abundância de árvores, dados de 17 quadras, representando 32,07\% do universo amostral. Foram utilizadas somente as amostras de 17 quadras, uma vez que estas, apresentavam todas as medidas necessárias para a análise quantitativa, as demais 36 quadras, foram retiradas da análise. Desta análise obteve-se 6.943,6 m de calçada com 298 árvores, com uma abundância de 43 árvores por quilômetro de calçada. Porém, os 53 quarteirões foram usados para os resultados qualitativos da arborização viária do município de Colorado,RS.

Rachid \& Couto (1999), encontraram 2.958 elementos (plantas vivas, plantas mortas e covas abertas) num total de 98,21 quilômetros de calçada e, com esta amostra, obteve-se uma estimativa de 30,12 árvores por quilômetro de calçada. Nossos resultados se apresentam com maior quantidade de árvores por quilometro de calçada, porém os dados de Rachid \& Couto (1999) são de um universo amostral maior e os mesmos contabilizaram covas abertas que não foram contempladas no presente trabalho.

Segundo Santamour Júnior (1990), a maior diversidade de espécies de árvores na paisagem urbana se faz necessária justamente para garantir o máximo de proteção contra PP(P) 
pragas e doenças; dessa forma, segundo esse mesmo autor, recomenda-se não exceder mais que $10 \%$ da mesma espécie, $20 \%$ de algum gênero e $30 \%$ de uma família botânica.

Meneguetti (2003) em trabalho realizado na Orla de Santos-SP obteve um índice de diversidade de Snannon-Weiner igual a 2,61 e, em trabalho realizado na estância turística de águas de São Pedro-SP, Bortoleto et al. (2007) obteve um índice de 3,90. O Índice obtido para a cidade de Colorado/RS foi de 2,95, o que demonstra uma diversidade intermediária entre essas duas cidades. Este valor pode estar indicando uma baixa diversidade da arborização viária do município, considerando as espécies exóticas que entraram na amostra.

Dentre as famílias amostradas, conforme a Figura 03, a que apresentou maior diversidade foi a Myrtaceae, sendo todas nativas.

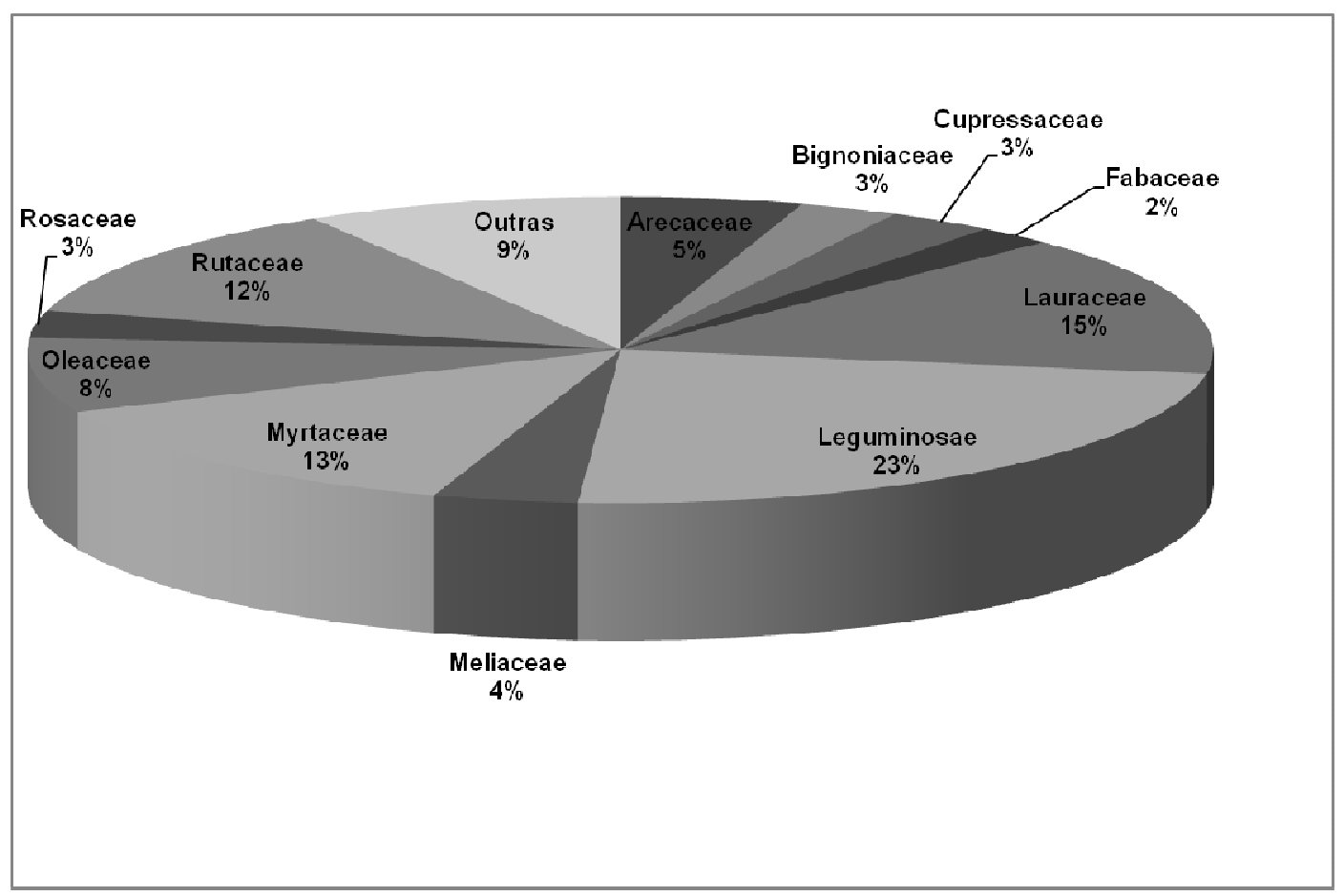

Figura 03. Principais famílias existentes na arborização urbana de Colorado, RS.

De acordo com Milano e Dalcin (2000), uma única espécie não deve ultrapassar o total de 10 a $15 \%$ de indivíduos arbóreos contidos em uma cidade, pois em ruas com plantios homogêneos, as árvores correm o risco de se tornarem alvos fáceis de pragas e doenças acarretando, desta forma, perdas para o meio urbano. Dentro desse aspecto, o Inga marginata foi a espécie predominante, representado por $21,12 \%$ dos exemplares registrados, fugindo às recomendações desses autores.

Dos 483 indivíduos amostrados e identificados grande parte são espécies frutíferas, tanto para exemplares nativos como exóticos, cito: guabijueiro (Myrcianthes pungens), cerejeira (Eugenia involucrata), laranjeira (Citrus sinensis), bergamoteira (Citrus deliciosa), 
entre outros, muito provavelmente plantados pelos próprios moradores. Costa et al. (1996), alertam quanto ao fato de árvores frutíferas não serem indicadas para o plantio em vias públicas, pois freqüentemente são susceptíveis a pragas, doenças e poluição.

Quanto aos aspectos físicos e sanitários (estado geral), pode-se classificar $24,64 \%$ dos exemplares como ótimos, $55,07 \%$ bons, $15,53 \%$ regulares, 3,73\% péssimos e, 1,03\% mortos.

A arborização de Colorado, RS possui $50,84 \%$ dos seus indivíduos arbóreos amostrados em bom estado fitossanitário, sem visualização de ataque por pragas como: ácaro, bactéria, broca, cochonilha, cupim, formiga, fungo, lagarta, pulgão e vírus e, 49,16\% das árvores com alguma forma de ataque (Tabela 02). Sendo que as árvores atacadas apresentam um ataque preferencial por formigas. Foram retirados da amostra 5 indivíduos classificados como mortos.

Tabela 02. Porcentagem dos tipos de ataques identificados nos representantes arbóreos na área urbana de Colorado, RS.

\begin{tabular}{lcc}
\hline \multicolumn{1}{c}{ Classes de Ataque } & $\mathbf{N}^{\mathbf{0}}$ indivíduos & $\boldsymbol{\%}$ \\
\hline Broca e Formiga & 13 & $5,51 \%$ \\
Formiga & 89 & $37,71 \%$ \\
Formiga e Fungo & 23 & $9,75 \%$ \\
Formiga e Lagarta & 24 & $10,17 \%$ \\
Fungo & 19 & $8,05 \%$ \\
Outros & 67 & $28,51 \%$ \\
\hline Total com ataque & 235 & $49,16 \%$ \\
Total sem ataque & 243 & $50,84 \%$ \\
\hline Total & $\mathbf{4 7 8}$ & $\mathbf{1 0 0 \%}$ \\
\hline
\end{tabular}

As calçadas mediram, em média, $2 \mathrm{~m}$ de largura, sendo que Souza et al. (2008), consideram como ideal uma largura de $3 \mathrm{~m}$, pois permite que as árvores desenvolvam-se sem danificar a estrutura dos muros e residências, além de facilitar a circulação de pessoas.

Outra análise importante realizada foi com relação à situação do sistema radicular. Do total de árvores amostradas, 351 não apresentam problemas com afloramento de raiz, sendo que $132(27,33 \%)$ apresentam sistema radicular superficial, ou seja, raiz parcialmente exposta causando danos significativos ao passeio público, conseqüência do pequeno espaço disponível para o crescimento das raízes, sendo que Santos e Teixeira (2001), recomendam que a área livre não seja inferior a $1 \mathrm{~m}^{2}$. Em inventário realizado no centro de 
Pato Branco/PR por Moccellin et al. (2006), 78\% dos indivíduos amostrados apresentaram nenhuma ou pequena área livre ao seu redor.

A falta de área livre (espaço livre que permite a infiltração de águas e nutrientes para a planta) provoca um mau desenvolvimento das plantas, e a utilização de espécies com sistema radicular pouco profundo numa área pequena, pode comprometer a calçada, devido à pressão exercida pelas raízes.

De acordo com Silva (2009), as árvores devem estar inseridas nos espaços urbanos disponíveis sem prejudicar outros. Entretanto em Colorado, RS, nem sempre esses critérios são obedecidos. Com relação ao posicionamento das árvores nas calçadas, pode-se observar que, nas ruas amostradas, 55 árvores estão localizadas no centro do passeio público, 68 junto à divisa e 360 junto à guia. Desta forma recomenda-se uma distância de 0,5 metros para árvores plantadas junto á guia, para que não haja interferência das raízes e copas nas ruas interferindo na passagem de veículos.

Silva (2002), recomenda o diâmetro da copa da espécie acrescido de um metro, ou quando se deseja uma sombra contínua, o indicado é que seja igual a do diâmetro da árvore no seu máximo desenvolvimento, sendo para a espécie de pequeno porte o ideal de 5 a 6 metros de distância, médio porte de 7 a 10 metros e de grande porte de 10 a 15 metros.

Dentre as situações inadequadas e presentes nos conflitos da arborização urbana no município de Colorado, RS, pode-se destacar o avanço da copa para a rua, o avanço da copa para a casa, entrelaçamentos de copas, larguras das ruas e passeios e problemas ocasionados pela raiz, não chegando a números consideráveis. O mesmo resultado foi encontrado por Melo et al. (2007) em diagnóstico qualitativo e quantitativo da arborização urbana realizado no Paraíba.

Com relação ao contato das árvores amostradas com a rede elétrica, 385 indivíduos não apresentam problemas com fiação e 97 indivíduos apresentam problemas relacionados com a fiação primária, secundária e telefônica, sendo o tipo de fiação mais atingida a secundária.

Após levantamento prévio no mapa oficial da cidade, constatou-se que o mapa não condiz com a realidade, sendo necessário um novo estudo para confecção de um novo mapa, atualizado.

O fato de haver predominância de poucas espécies na arborização de vias públicas traz sérias conseqüências para a biodiversidade do ecossistema urbano, considerando-se que a diversidade da vegetação é de suma importância para a ampliação e fixação da fauna e a manutenção do equilíbrio ecológico (Pereira et al., 2005).

Com todos os dados e análises em mãos, criou-se um banco de dados, em planilhas do EXELL, onde foram inseridas todas as espécies arbóreas registradas no município e 
suas respectivas condições fitossanitárias, sendo que estes dados foram fornecidos ao Departamento Municipal de Meio Ambiente para que sejam freqüentemente atualizados, podendo desta forma, o órgão manter um controle da situação.

\section{CONCLUSÕES}

A análise dos resultados obtidos mostra que das 483 espécies inventariadas, a mais freqüente foi o Ingá-feijão (Inga marginata).

O município de Colorado, RS possui uma arborização urbana com baixa diversidade. Em número de espécies, as plantas nativas são mais predominantes na arborização da cidade, porém existe grande número de exemplares exóticos. Levando-se em conta que o cálculo da diversidade incluiu as espécies exóticas, considera-se necessário a troca oportuna de exemplares exóticos por nativos uma vez que resultaria no aumento da diversidade arbórea do município, pois uma maior diversidade garante uma maior proteção dos exemplares ao ataque de pragas e doenças, contribui para a manutenção da avifauna local e contribui para a conservação das espécies e da biodiversidade.

A arborização necessita de reparos, pois grande parte das espécies apresenta alguma forma de ataque e injúrias.

Alguns exemplares, devido a sua altura, estão prejudicando a rede elétrica.

Existe a necessidade de ampliação dos canteiros, pois alguns exemplares arbóreos estão danificando calçadas, necessitando de reparos.

Existe a necessidade de maior área livre na base do tronco. Também se observaram conflitos entre a copa das árvores e a rede de energia elétrica.

Considera-se indispensável o planejamento da arborização urbana e a realização de um plano, prevendo critérios e técnicas adequadas de plantios e manutenções.

A arborização na cidade de Colorado, RS apresenta diversos problemas relacionados à abundância e escolha das espécies utilizadas, fato comum para diversas cidades brasileiras. Para este problema, recomenda-se a elaboração de uma listagem de espécies sugeridas para plantio em diferentes situações, para orientar a comunidade em geral e a implementação de um plano municipal de arborização urbana, de forma que este seja realizado coordenadamente pelo Departamento Municipal de Meio Ambiente, estabelecendo regras, acompanhando e controlando de maneira efetiva. 


\section{REFERÊNCIAS BIBLIOGRÁFICAS}

BORTOLETO, S.; DA SILVA FILHO.; D. F.; LIMA, A. M. L. P. Prioridades de manejo para a arborização viária da estância de Águas de São Pedro - SP, por setores. Revista da Sociedade Brasileira de Arborização Urbana, v.1, n.1, p. 62-73, 2006.

COSTA, L. M. S. A.; FILHO, L. E. M.; FARAH, I. M. C.; CAMISÃO, C. Arborização das ruas do bairro de Copacabana. In: $3^{\circ}$ CONGRESSO BRASILEIRO SOBRE ARBORIZAÇÃO URBANA, Bahia. Anais. Bahia: SBAU, 1996. p. 79-88.

DANTAS, I. C.; SOUZA, C.M. C. Arborização urbana na cidade de Campina Grande-PB: Inventário e suas espécies. Revista de Biologia e Ciências da Terra. v.4, n.2, 2004.

GRAZIANO, T. T. Viveiros Municipais. Departamento de Horticultura - FCAVJ-UNESP. Notas de aula, 1994.

IBGE - BRASIL. Ministério do Planejamento, Orçamento e Gestão. Instituto Brasileiro de Geografia e Estatística. Contagem Populacional 2007. Disponível em: http://www.ibge.gov.br/cidadesat/topwindow.htm?1. Acesso em: 09 set 2009.

LORENZI, H. Árvores Brasileiras: manual de identificação e cultivo de plantas arbóreas do Brasil. 4.ed. Nova Odessa,SP: Instituto PLantarum, 2002a. v.1, 384p.

LORENZI, H. Árvores Brasileiras: manual de identificação e cultivo de plantas arbóreas do Brasil. 2.ed. Nova Odessa,SP: Instituto PLantarum, 2002b. v.2, 384p.

LORENZI, H.; SOUZA, H. M, de.; TORRES, M. A. V.; BACHER, L. B. Árvores exóticas no Brasil: madeiras, ornamentais e aromáticas. Nova Odessa, SP: Instituto Plantarum, 2003. v.1, 368p.

MELO, E. F. Q.; ROMANI, A. Praça Ernesto Tochetto: Importância da sua preservação histórica e aspectos de sua arborização. Revista da Sociedade Brasileira de Arborização Urbana. Piracicaba. v.3, n.1, 2008. p.54-72.

MELO, R. R.; LIRA FILHO, J. A.; JÚNIOR, F. R. Diagnóstico qualitativo e quantitativo da arborização urbana no Bairro Bivar Olinto, Patos, PR. Revista da Sociedade Brasileira de Arborização Urbana. Piracicaba. v.2, n.1, 2007. p.64-80.

MENEGUETTI, G. I. P. Estudo de dois métodos de amostragem para inventário da arborização de ruas dos bairros da orla marítima do município de Santos, SP. Dissertação (mestrado) - Escola Superior de Agricultura "Juiz de Queiroz", Universidade de São Paulo, para a obtenção do título de Mestre em Recursos Florestais, Piracicaba, 2003. 
MILANO, M. S. Planejamento da arborização urbana: relação entre áreas verdes e ruas arborizadas. In: ENCONTRO NACIONAL DE ARBORIZAÇÃO URBANA, 3., Curitiba, 1990. Anais... Curitiba, 1990. p. 60-71.

MILANO, M. S. Métodos de amostragem para avaliação de ruas.In: Congresso Brasileiro sobre Arborização Urbana, 2, São Luiz, 1994. Anais... São Luiz: SBAU, 1994. p.163-168.

MILANO, M,; DALCIN, E. Arborização de vias públicas. 1.ed. Rio de Janeiro: LIGHT, 2000. 226p.

MOCCELLIN, R.; SILVA, L. M.; WEISSHEIMER, D. I.; ZBORALSKI, A. R.; FONSECA, L. Situação da arborização do centro da cidade de Pato Branco - PR. In: XI Seminário de Iniciação Científica e Tecnológica - Universidade Tecnológica Federal do Paraná, 2006. Anais...Curitiba: CD-ROM.

PEREIRA et al. O uso de Espécies Vegetais, como Instrumento de Biodiversidade da Avifauna Silvestre, na Arborização Pública: o caso de Recife. Atualidades Ornitológicas. Olinda, n. 125, p. 1-15, maio/junho, 2005.

PREFEITURA MUNCICIPAL DE COLORADO - RS. Mapa cadastral da cidade, 2004. Colorado/RS.

RACHID, C.; COUTO, H. T. Z. Estudo da eficiência de dois métodos de amostragem de árvores de rua na cidade de São Carlos, SP. Scientia Florestalis. São Paulo. n.56, p.5968, dez. 1999.

SANTAMOUR JÚNIOR, F.S. Trees for urban planting: diversity uniformity, and common sense. In: METRIA CONFERENCE, 7., 1990, Lisle. Proceedings. Lisle: 1990. p.57-66.

SANTOS, N. R. Z.; TEIXEIRA, I. F. Arborização de Vias Públicas: Ambiente x Vegetação. Santa Cruz: Pallotti, 2001.

SILVA, E. M. Estudo da arborização urbana do bairro Mansour, na cidade de Uberlândia/MG. Caminhos de Geografia - Revista on line, Fevereiro - 2002. Disponível em: www.ig.ufu.br/revista/volume05/artigo06_vol05.pdf. Acessado em 01 de outubro de 2009.

SOUZA, M. A. L. B.; LASCHI, D.; BUENO, O. C.; GABRIEL, J. L. C. Inventário da arborização urbana de vias públicas da cidade de Botucatu. In: ENCONTRO NACIONAL SOBRE ARBORIZAÇÃO URBANA, 3., 1996, Curitiba. Anais ... Curitiba, PR: Sociedade Brasileira de Arborização Urbana. 1996, p. 196-199.

SOUZA, E. S.; COSTA, C. V. B. da.; CARNEIRO, M. J. C.; SILVA, M. M. da. Caracterização da arborização urbana da cidade de Altamira-PA. Altamira, 2008. 
TAKAHASHI, L. Y. Arborização urbana: inventário. In: CONGRESO BRASILEIRO DE ARBORIZAÇÃO URBANA, 2., 1994, São Luís. Anais... São Luís: Sociedade Brasileira de Arborização Urbana, 1994. p. 193-200.

VILLARINHO, F. M.; MACEDO, R. L. G.; TOMIAZZI, A. B. Avaliação da opinião pública sobre a arborização do bairro de Jacarepaguá - Freguesia, Município do Rio de Janeiro, RJ. In: IX CONGRESO BRASILEIRO DE ARBORIZAÇÃO URBANA, 2005. Belo Horizonte. Anais ... Belo Horizonte, MG, 2005. 